\title{
THE PERCEPTION OF ROBOT'S EMOTIONAL GESTURES AND SPEECH BY CHILDREN SOLVING A SPATIAL PUZZLE ${ }^{1}$
}

Zinina A. A. (zinina_aa@nrcki.ru),

Zaidelman L. Y. (zaydelman_ly@nrcki.ru),

Kotov A. A. (kotov_aa@nrcki.ru),

Arinkin N. A. (arinkin_na@nrcki.ru)

Kurhcatov Institute; Russian State University for the Humanities, Moscow, Russia

The emotional behavior of a companion robot is important for human-robot interaction in the situation of training tasks. We examined the influence of emotional gestures and emotional speech of the robot on its perception by primary school students ( $N=52$, male, female, mean age 9.8 ) in the situation of joint solution of the spatial Tangram puzzle. It was shown that emotional gestures make a significant contribution to the attractiveness of the robot for the child. It was also found that test subjects prefer the robot with emotional gestures and speech over the robot with neutral gesture and speech behavior. The study also analyzed the communicative behavior of children, identified typical communicative signs that are typical for interaction start with the robot, for monitoring the game and for difficult situations. We described typical mistakes that children make when assembling a puzzle together with the robot.

Keywords: multimodal communication, robot-to-human interaction, affective robot tutors

DOI: $10.28995 / 2075-7182-2020-19-811-826$

1 The research is supported by the Russian Science Foundation (project No 19-78-00113). 


\title{
ВОСПРИЯТИЕ ЭМОЦИОНАЛЬНЫХ ЖЕСТОВ И РЕЧИ РОБОТА ДЕТЬМИ, РЕШАЮЩИМИ ПРОСТРАНСТВЕННУЮ голОВОЛОМКУ
}

\author{
Зинина А. А. (zinina_aa@nrcki.ru), \\ Зайдельман Л. Ю. (zaydelman_ly@nrcki.ru), \\ Котов А. А. (kotov_aa@nrcki.ru), \\ Аринкин Н. А. (arinkin_na@nrcki.ru) \\ Курчатовский институт; Российский государственный \\ гуманитарный университет, Москва, Россия
}

\begin{abstract}
Эмоциональное поведение робота-компаньона важно при взаимодействии человека и робота в ситуации решения обучающих задач. В рамках эксперимента ( $N=52$, муж., жен., средний возраст 9,8) исследовалось влияние эмоциональных жестов и эмоциональной речи на восприятие робота младшими школьниками. Было показано, что именно эмоциональные жесты вносят существенный вклад в привлекательность робота для ребенка. Также обнаружено, что испытуемые скорее предпочитают робота с эмоциональными жестами и речью по сравнению с роботом с нейтральным жестовым и речевым поведением. В рамках исследования также было проанализировано коммуникативное поведение детей при решении пространственной головоломки Танграм, выделены типичные коммуникативные знаки у детей, характерные для начала взаимодействия с роботом, контроля хода игры, затруднительных ситуаций. Описаны типичные ошибки при совместной сборке головоломки с роботом.
\end{abstract}

Ключевые слова: мультимодальная коммуникация, взаимодействие между роботом и человеком, роботы-наставники

\section{Introduction}

Robots with social skills are increasingly used in various fields of education. Learning with robots is called "r-Learning" [Han et al., 2008]. In a situation of learning, robot can act as a mentor, a tool, or an equal partner [Mubin et al., 2013]; [Kanda et al., 2004]. Robots are used for teaching natural sciences [Shiomi et al., 2015], mathematics [Brown, Howard, 2014] and music [Han et al., 2009]. It is noted that robots are effective for language learning [van den Berghe et al., 2019]; [Belpaeme et al., 2018b]. In [Park et al., 2017] it is shown that interaction with a social robot acting as an equal partner (peer) can contribute to the development of cognitive skills among children. In many interaction situations, robots are more interactive and user-friendly than computers [Kanda et al., 2004]; [2014]; [Alemi et al., 2014]; [Belpaeme et al., 2018a]. As compared to software applications, social robots greater involve children in learning, increase their motivation and curiosity, as well as the number of emotional responses [Kanda 
et al., 2004]; [Gordon et al., 2015]; [Wainer et al., 2006]. Robots can demonstrate various means of communication: using gestures, movements, and facial expressions, which also helps to increase the interest and motivation of users to any training. In [Han et al., 2008], using the example of English lessons, it is shown that home robots are more effective than other types of learning tools (such as books or audio recordings): children show interest in learning, better concentration, and increased academic performance. In addition, children feel that a home robot is more friendly than other educational material. In [Han, Kim, 2009], it is shown that the robot's cheering is especially important for children. In [Brown, Howard, 2014], the robot uses different verbal encouragement strategies when teaching maths to maintain the level of student engagement. The authors assume that educational robots should monitor student involvement and apply behavioral strategies (verbal or nonverbal cues) when involvement decreases. In our study, the robot acts as a child's assistant when solving a puzzle. Thus, the robot controls the solution of the problem: it introduces puzzle to the child, gives instructions, and monitors the progress. Here we follow [Leyzberg et al., 2012], where a robot also acted as an instructor in solving the puzzle. The authors showed that a physical robot is quite effective as a mentor. In addition, the advantages of a physical robot are highlighted in [Wainer et al., 2006] when performing in Hanoi puzzle.

Several researchers emphasize the importance of nonverbal behavior for educational robots. In [Kennedy et al., 2015b], the robot helped children determine whether numbers are prime. The authors showed that children who interact with a robot that exhibits more complex nonverbal behavior show great learning success. On the other hand, the same authors [Kennedy et al., 2015a] note that while the robot's learning strategy is effective, adding social and adaptive behaviors does not lead to a significant increase in efficiency. Therefore, although the presence of a physical robot leads to the improved learning progress, the performance of social behavior by a robot in the context of learning requires caution.

Even though affective robot mentors have great potential in the field of education, many researchers pay special attention to the development of an emotional robot model [Cuadrado et al., 2019]; [Schodde et al., 2017]. For example, in [Leite, Pereira, 2007] iCat robot played chess with a child. The robot's emotional state and expression is affected by every move of the child. The authors showed that in this situation "children may then interpret the characters affective behavior and by that acquire additional information to understand the game better and thus to improve their chess skills". In another paper [Pereira et al., 2010], the robot comments on the moves of two chess players, showing sympathy for one of them and a neutral attitude to the other. The results of an experimental study show that users who were empathized with the robot were more likely to perceive the robot as a friend. Thus, modeling emotional and empathic behavior is one of the key characteristics of an educational robot. Moreover, emotional behavior can be modeled not only by emotional statements, but also by emotional mimic and gesture reactions. In our work, we decided to test the effect of robot's emotional gestures and speech on participants in an experimental study. We assumed that participants would prefer the robot that helps them and uses emotional communicative actions. The study was conducted using F-2 robot, an experimental platform for studying the interaction between humans and robots [Zinina et al., 2019]. 


\section{Research procedure}

We conducted an experiment in which we evaluated the impact of emotional gestures and emotional speech on the attractiveness of the robot to a user. A separate goal of the experiment was to investigate the complex communicative behavior of test subjects when solving a spatial puzzle. In this experiment two robots helped participants to complete a Tangram puzzle. This puzzle is a well-known experimental media for studies of natural human communication [Clark, Wilkes-Gibbs, 1986], development of linguistic resources [Shore et al, 2018] as well as for the design of robot communicative strategies [Kirschner et al., 2016].This puzzle is also familiar to primary school students, which helps to increase their interest and motivation to learn. The puzzle consists of 7 elements of different color, shape, and size (two big triangles: red and blue; two small triangles: yellow and dark blue; a middle green triangle, an orange parallelogram, and a purple square). The task of a participant was to arrange the elements within a given contour on a white sheet. During the experiment, the participant was to complete: Parallelogram, Fish, Triangle, and Ship figures. The robot was located on the table in front of the participant and used speech instructions, gestures, and gaze, instructing the participant to put a certain element on a certain place. A human assistant was present in the experiment situation, but his communication with the subjects was minimal: the robot itself greeted a child, repeated the rules of the game, gave instructions, and asked to move to another robot after a figure is finshed. At the beginning of the experiment, the test subject sat in front of one of the robots (Fig. 1), the robot was selected randomly. In the experiment the robot introduced the rules of Tangram puzzle, pointed to each element of the puzzle, and repeated its name, for example, "on the right there are two big triangles and a parallelogram". Then the robot helped the child to solve two tasks. For example, the robot might say "take this big triangle and put it in the lower right corner". Then the robot asked him to move to another robot. Another robot also introduced itself the child, helped him to solve the other two tasks and completed the experiment. The experiment was conducted in Russian. The behavioral scripts of the robot were organized as sequences of BML (Behavior Markup Language) packets: one sequence per task. The average time of the experiment was 15 minutes. After interacting with robots, the experimenter asked the children to choose the preferred condition (robot) and rate the robots in each of the two experimental conditions on five-point semantic differential scales, and then questioned about the difference in robot's behavior in detail. In addition, the objective indicators were recorded- the speed of solving each task and the number of participants' mistakes. The whole experiment was recorded from two viewpoints: front view of the experimental situation (Fig. 1a) and the side view of a player (Fig. 1b).

The experiment was organized in the paradigm of the Wizard of Oz [Kelley, 1984] in which the moves by the player were evaluated as successful or not by a remote human operator. After the operator had indicated a successful move, the robot chose a communicative pattern to praise the user and explained the next move. If a participant was mistaken, the operator indicated that to the robot, and the robot chose a communicative pattern to indicate an error and repeated the instruction. If the user solved the whole figure before the end of BML protocol, the operator gave a command to the robot, and the robot chose a communicative pattern to praise the participant for the successful task. 


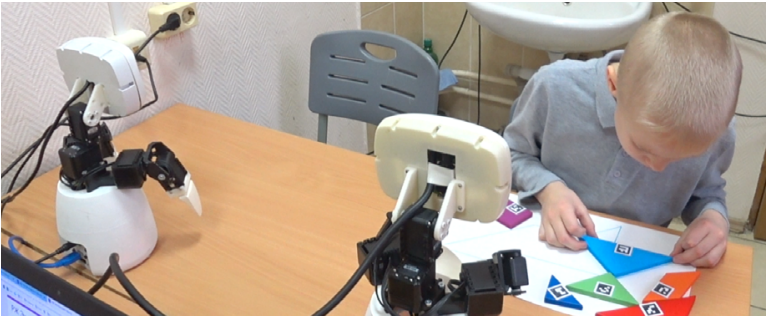

Fig. 1 (a). Experimental setup: front view

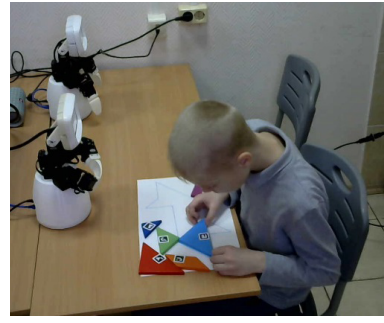

Fig. 1 (b). Experimental setup: side view

\section{Experimental conditions}

In the experiment two independent variables varied, each with two levels: robots demonstrated expressive (emotional) or neutral gestures, robots could also react with emotional or neutral statements (Fig. 2).

In one experimental series the child interacted with two robots whose behavior was different:

(i) emotionality of gestures-we compared the conditions: (a) $\times$ (c) and (b) $\times$ (d). The robot with neutral gestures was opposed to the robot with emotional gestures, while the speech of two robots could be emotional or neutral, but the same for the two robots in each trial. Gestures varied only in the communicative reaction to the subject's actions, in the part where the robots gave instructions, the gestures did not differ.

(ii) emotionality of speech -we compared the conditions: (a) $\times$ (b) and (c) $\times$ (d). The robot with neutral speech was opposed to the robot with emotional speech, while the gestures of two robots could be emotional or neutral, but the same for the two robots in each trial.

(iii) emotionality of gestures and speech-we compared the conditions: (a) and (d). The robot that demonstrated emotions in gestures and speech was opposed to the robot with neutral gestures and speech.

Tasks with different experimental conditions were presented in random order.

Robot with emotional speech. This robot used emotional interjections, expressed emotional evaluation of user's actions and game situation (Ah, what a beautiful figure we have got!), or indirectly evaluated the interlocutor (Wow, you are doing great!). Negative politeness strategies were used in speech responses to erroneous user actions [Brown, Levinson, 1987]. For example, We have the wrong element ("rise common ground" strategy), Oh, a bit wrong ("reduce the imposition" strategy).

In its neutral speech, the robot only briefly evaluated the subject's actions using particles or predicates: for example, Yes, Aha, Ok and Wrong, No, Not here. The robot did not evaluate the child and did not describe his own emotions. 
Emotional gestures for robots were developed based on the REC corpus. In this experimental condition, the robot accompanied speech with actions directed at the addressee and used gestures with such communicative functions as joy, appeal and demonstration. In a condition with neutral gestures, the robot accompanied speech with the imitated breathing and gestures typical to communicative function compensation-closing - e. g. joined hands in front of the body, imitated scratching of the body.

\section{Speech}

Emotional speech

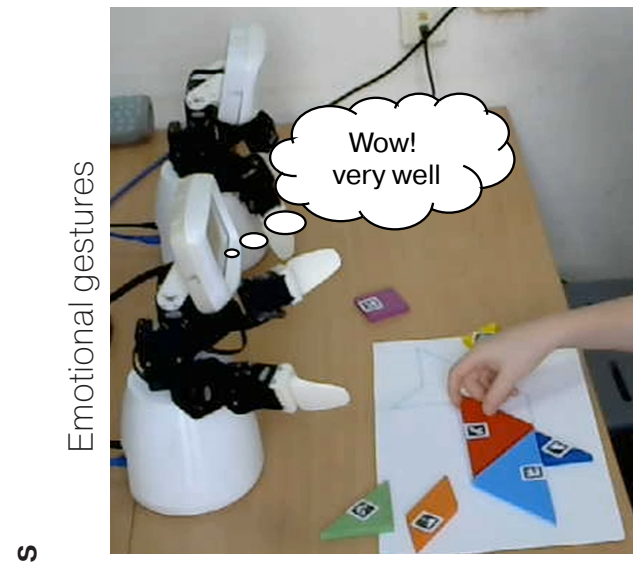

(a)

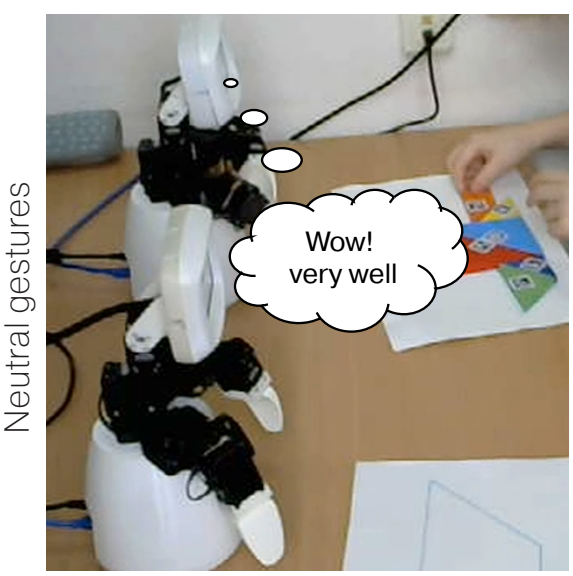

(C)
Neutral speech

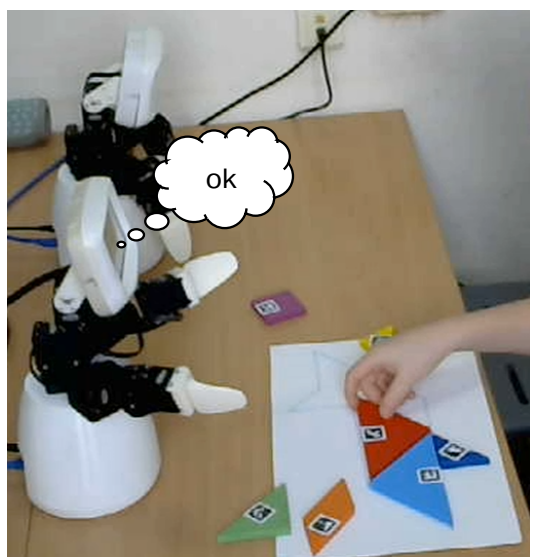

(b)

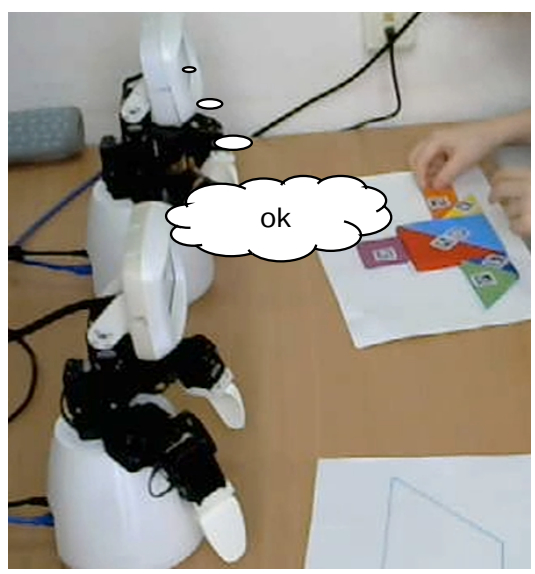

(d)

Fig. 2. Experimental conditions 


\section{Participants}

Participants of the experiment were $4^{\text {th }}$ degree pupils of an elementary school: 52 children, 18 girls and 34 boys, most of the participants were 10 years old, min. age 8, max. age 11. All subjects received informed consent from their parents. After the experiment, the children received a sweet prize. In the experimental study we focused on children of primary school age: this age is important because at this age educational activity replaces playing activity as the leading activity according to the modern periodization of mental development [Elkonin, 1951]. Also, 10-yearold schoolchildren seem to be an interesting group for analysis since not all of them have fully formed the required shape rotation operations - therefore, the robot acts as a valuable assistant and mentor. This group, on the one hand, is focused on getting new knowledge and on the other hand, younger students are easily carried away by an interesting, playful, but rather difficult task.

\section{Reaction to the emotional robot}

According to the analysis of variance, gestures are the key factor that influences the attractiveness of the robot for the children: $F=5.3, p=0.02$ (Fig. 3). Among the participants who compared robots with different gesture strategies, this difference was correctly described in $31.6 \%$ of cases: where the subjects have noted that two robots differ in gestures (only $10.5 \%$ of the subjects reported that the robots did not differ). At the same time the participants have noted in the reports that the robot with emotional gestures seems to be more sociable, funny and helpful, explains more clearly and is generally kinder.

When varying the emotionality of speech, $63.2 \%$ of children correctly described the difference: they noted that robots spoke differently and used different words (only $15.8 \%$ of subjects reported that they did not notice a difference in the behavior of robots). The subjects also noted that robots have different characters: the robot with emotional speech is more kind and polite. The participants suggested that the robot resembles a child. Some children noted that the robot with neutral speech is more rigorous and should communicate in a "children's language". Other subjects described the robot with neutral speech as more modern, close to the speech of school children. Even though children more definitively noted the difference between robots with emotional and neutral speech, this did not affect their preferences. The differences between the groups of subjects who prefer a robot with emotional speech and a robot with neutral speech were not significant.

When combining the two experimental conditions (fully emotional and fully non-emotional robot), $64.3 \%$ of children correctly described the difference between the robots. None of the subjects said that the robots behaved the same way. The children noted that the robot with emotional speech and gestures is more kind, empathic, uses interesting words. Differences in evaluations of the robot with emotional gestures and speech as compared to the robot with neutral behavior are statistically significant ( $\mathrm{t}=2.4, \mathrm{p}=0.02$ ) (Fig. 4). 


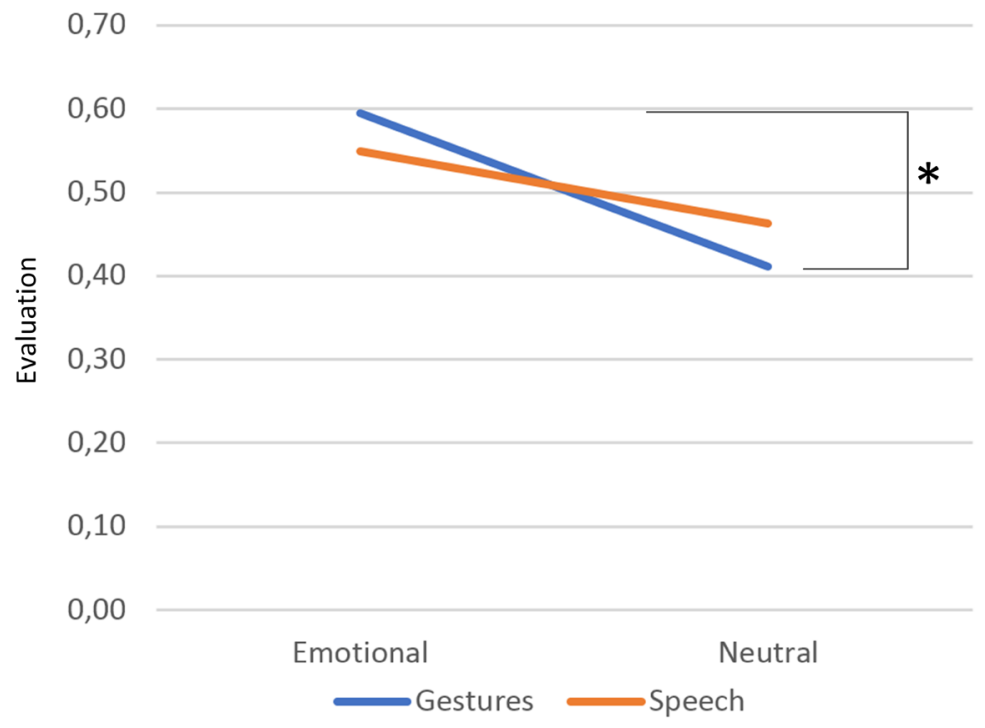

Fig. 3. Differences between robots with emotional performance in gestures or speech $(p<0,05)$

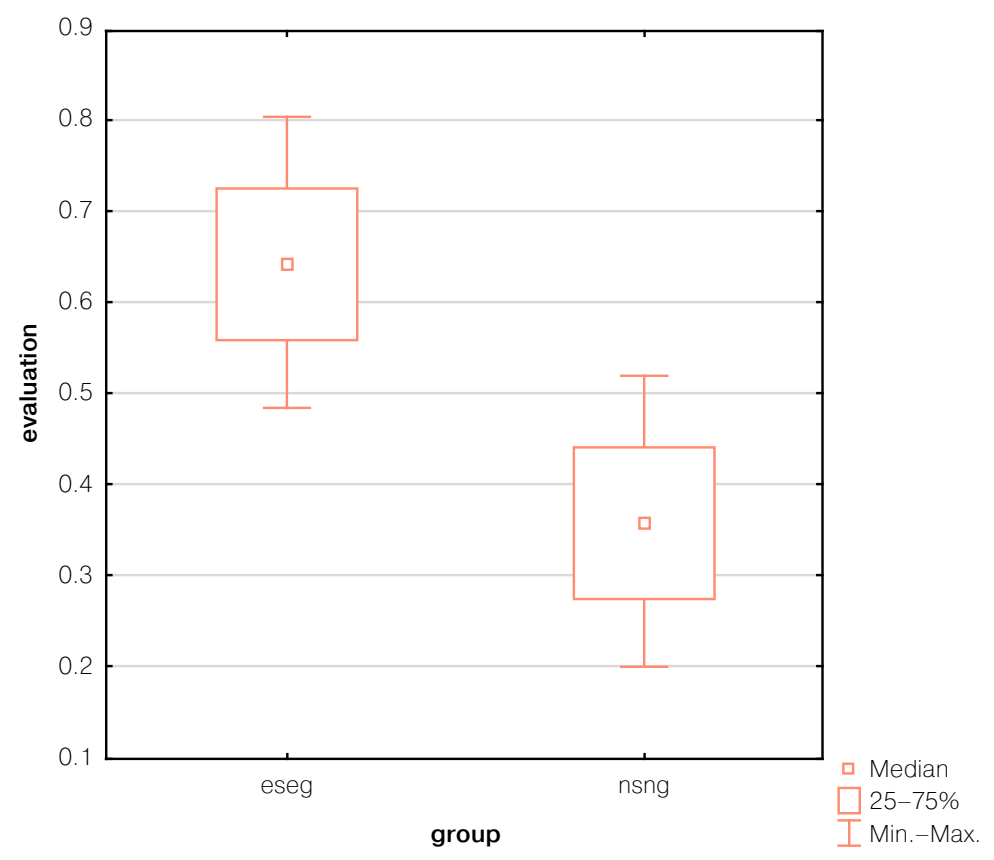

Fig. 4. Differences between the robot with emotional gestures and speech (eseg) and the robot with neutral gestures and speech (nsng) $(p<0.05)$ 
Based on the obtained data, we can conclude that the difference in speech is more obvious to the participants. The difference in gestures is more difficult to recognize. At the same time, the difference in gestures has the major contribution to the attractiveness of a robot to a child: children more often prefer the robot that demonstrates emotional gestures, even if they cannot accurately describe the difference between the experimental conditions. The insensitivity of user preferences to varying emotionality in speech can be explained as follows. Regardless of the emotionality of speech, the robot performed its functions as a tutor-the robot informed the person of correct or erroneous actions and, as a result, led the person to solving the puzzle. The emotionality of speech was well differentiated by the users but was considered secondary for solving the problem. The use of gestures by the robot was recognized by the subjects less definitively, it was not essential for the process of solving the problem, but it influenced the assessment of the robot by a person. The emotionality of gestures did not affect the process of solving the puzzle, but it affected human evaluation of the robot. This may indicate a more subtle, implicit influence of gestures on the preferences of subjects.

The proportion between the number of subjects who noted the difference between the robots and the number of subjects who were able to describe this difference is quite interesting (100\% of children said that there is a difference, $64.3 \%$ correctly described this difference). It can be assumed that the execution of the experiment at school affects children's answers: to the question Did the robots behave differently? the pupils usually assumed that the difference did exist. Perhaps it is advisable to evaluate the distribution of estimates on robots that are completely identical.

We assume that weak influence of the robot's emotional speech on the subjects' preferences can be explained by the theory of politeness [Brown, Levinson, 1987]. According to the theory, in a critical situation one uses fewer politeness strategies and more categorical instructions. Therefore, the restrained (non-emotional) speech behavior of the robot is acceptable and correct in the urgent situation of problem solving-and is not considered as rude. In addition, some subjects noted that the robot with non-emotional speech looks more "modern".

\section{Children's communicative behavior during interaction with the robot}

To assess the affective reaction of children to the robots, we calculated the number of smiles in each of the experimental conditions. It turned out that the condition with emotional gestures and neutral speech has the greater number of smiles among other conditions. The robot using emotional speech also causes on average the greater number of smiles than the robot using neutral speech in combination with neutral gestures (Fig. 5). It is also important to note that the first robot in various experimental conditions caused more smiles.

While assisting a user in solving a puzzle, the robot tells which element to take and where to place it. Therefore, subjects can request feedback when they select a game element and when they put it on the game field. To control the correct choice of the game element, the children can raise and show the element to the robot. At the same time, respondents could perform actions specific to the feedback request, for 
example, tilt their head, raise their eyebrows, tilt the whole body towards the robot. In addition, children could raise the element and shake it several times in the air, trying to attract the attention of the robot, or directly ask the robot This? (Fig. 6).

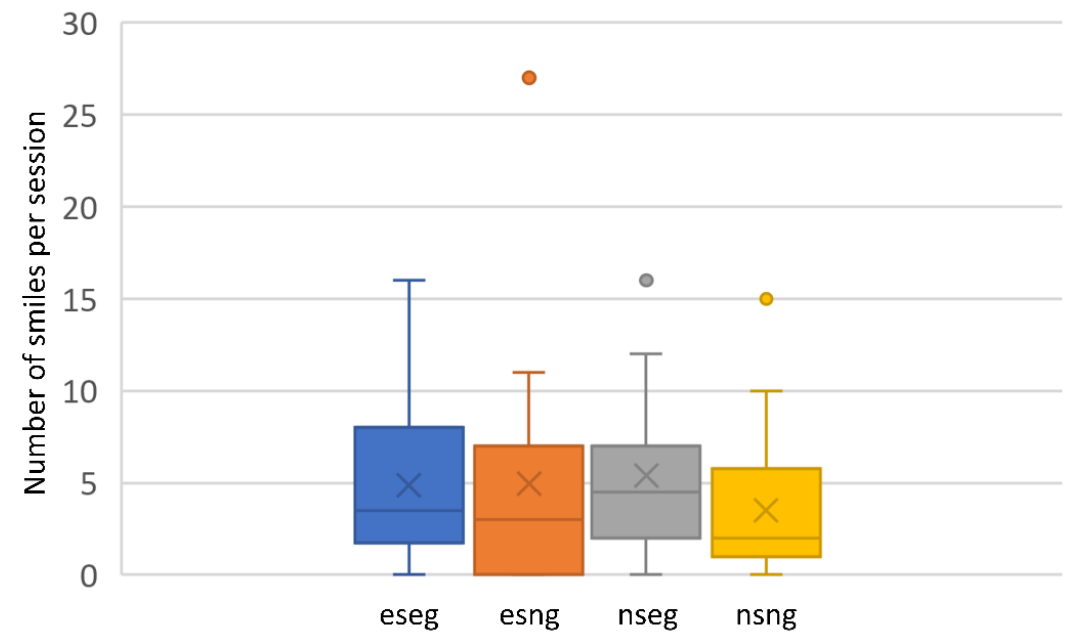

Fig. 5. Distribution of smiles in different experimental conditions: eseg —emotional speech and gestures; esng —emotional speech and neutral gestures; nseg neutral speech and emotional gestures; nsng — neutral speech and gestures
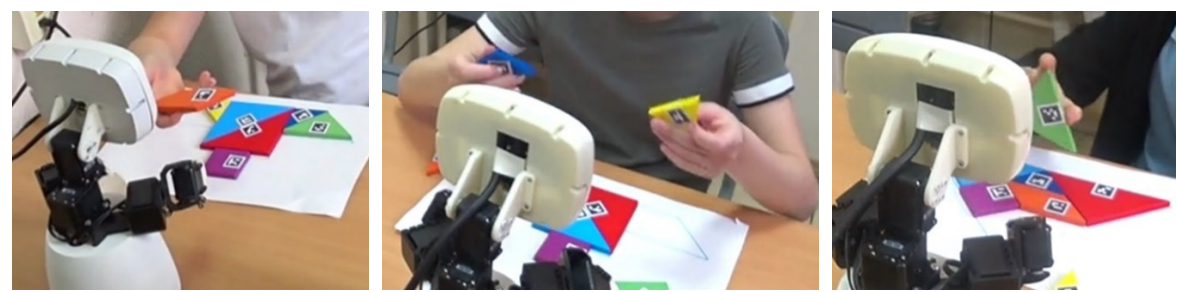

Fig. 6. Children try to attract the robot's attention

Participants also mark up the placement of the game element on the playing field with special gestures to inform the robot that the action has ended.

(i) Children retract hands from the playing field or clasp hands at the chest level (Fig. 7).

(ii) After placing the game element, the participants additionally touched it with their fingers (with the same or different hand). The element did not move, so these gestures are communicative (Fig. 8). 

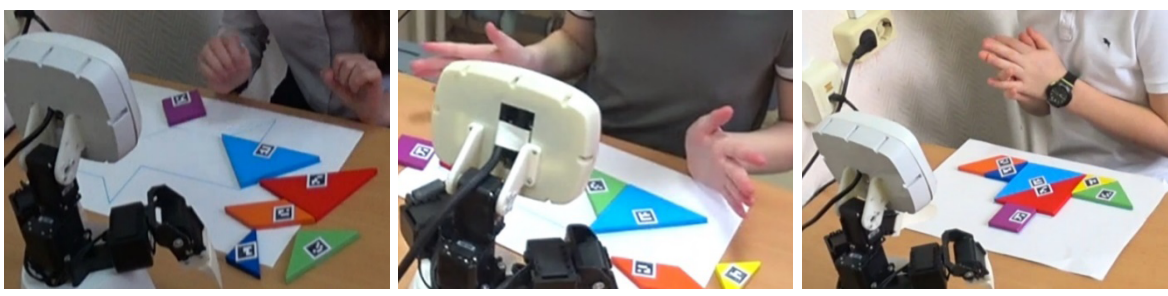

Fig. 7. Children try to inform the robot that the action is complete
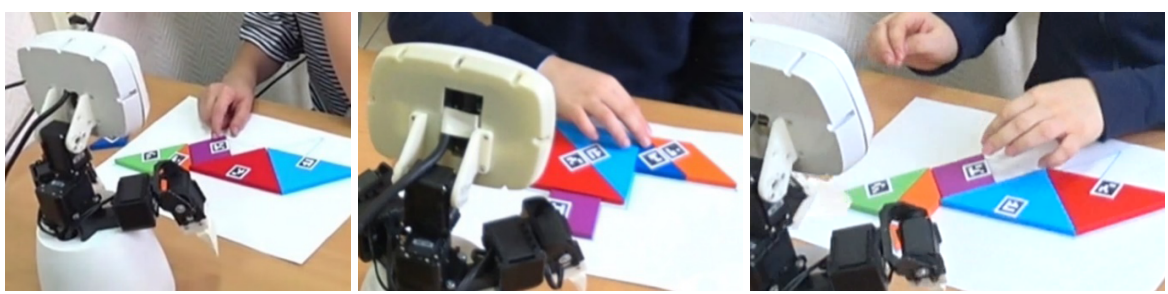

Fig. 8. Children try to inform the robot that the action is complete by additionally touching the element

\section{Typical mistakes}

Fish figure took the longest time to complete (on average 2 minute 16 seconds). The simplest figure for the participants was the Triangle (1 minute 32 seconds) (Fig. 9).

Fish was also the most complex figure-the participants made most of the mistakes while completing this figure -59 errors. In the parallelogram, 26 errors were made, in the ship-24, in the triangle 20 (Fig. 10).

The parallelogram is the only non-symmetrical element in the Tangram puzzle: after flipping it has a different shape, which is used in most of game figures. We found that the flipping of parallelogram causes the difficulties to many children. This may indicate the lack of skill to flip the figure in order to get a different shape. Sometimes it is more acceptable for subjects to change the arrangement of the game elements on the field than to flip the parallelogram to the other side (Fig. 11). The detection of such missing skill and their development may serve as one the basic strategies of r-Learning. 


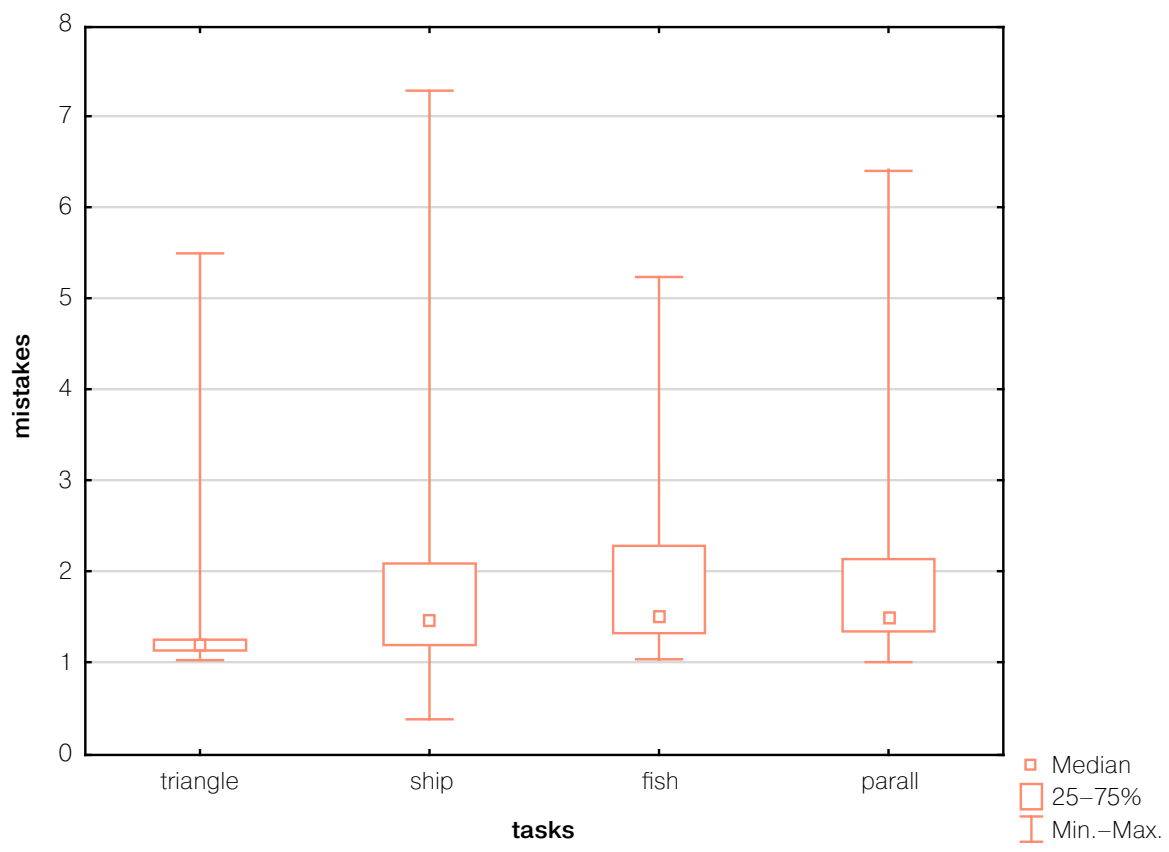

Fig. 9. Tasks solving time (min)

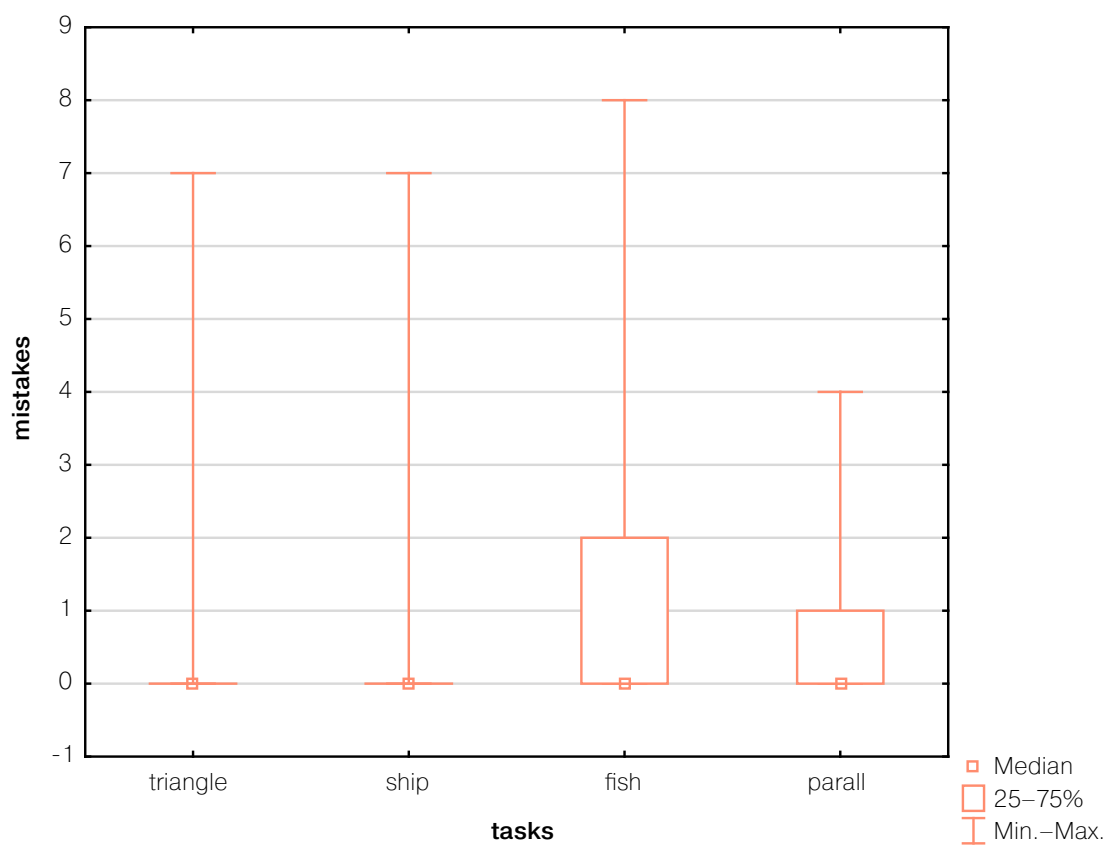

Fig. 10. The number of mistakes 

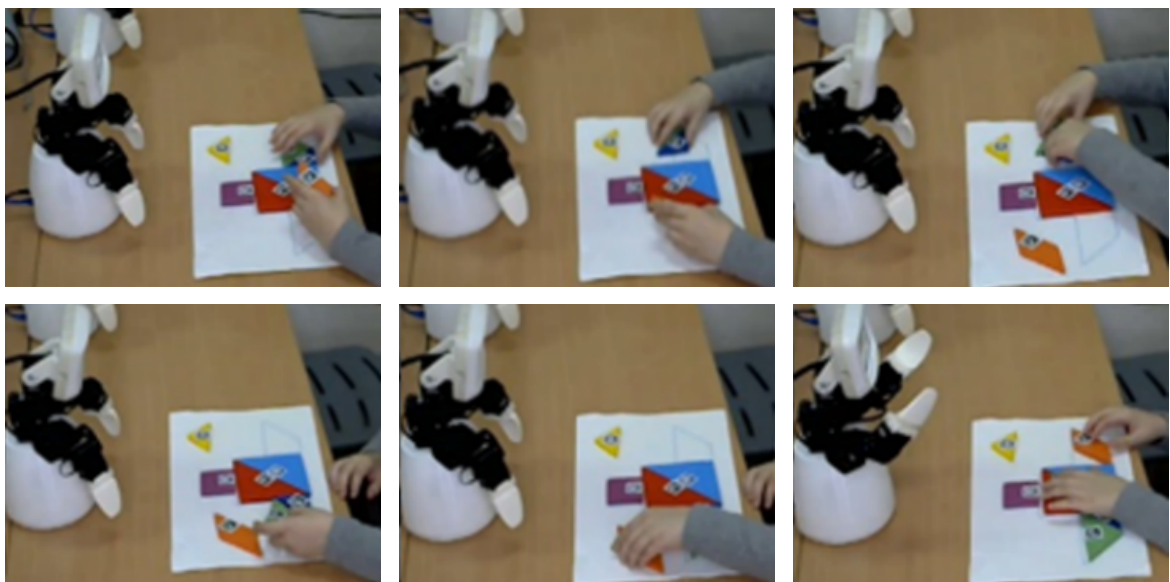

Fig. 11. Mistakes with the parallelogram

The child cannot place the parallelogram on the left side of the figure without flipping it over to the other side. He prefers to move already assembled elements from the right side to the left side in order to

place the parallelogram on the right in its current orientation

The second type of mistakes comes from the difficulties in formation of chunks of several game elements. For example, when assembling the Ship, children need to compose a big square of two big triangles and place it in the center of the contour. The subjects either cannot cope with the first instruction, or they cannot put the resulting combination in the right place of the contour.

The third type of mistakes is related to the ambiguity of the instructions. For example, when the robot asked a subject to put the parallelogram to the middle triangle (the middle-sized triangle in the game set), children often leaned it against the triangle that was in the middle of the present assembly (Fig. 12).

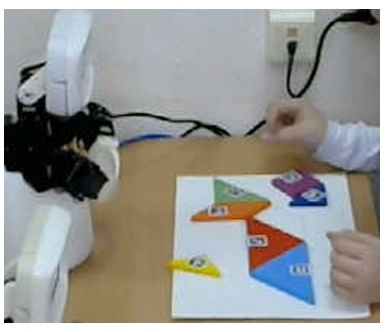

Fig. 12 (a). Correct position of the parallelogram
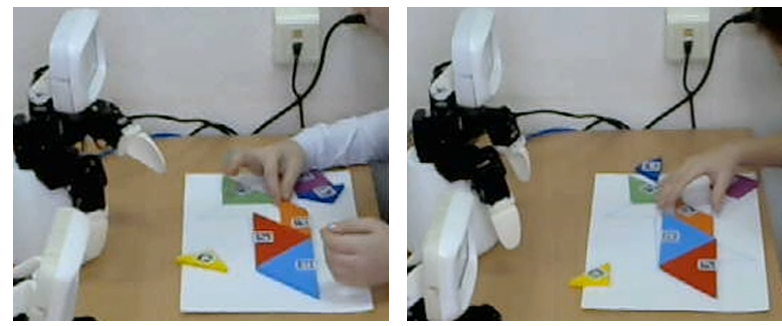

Fig. 12 (b). Incorrect positions of the parallelogram

Regular errors associated with misunderstanding or lack of skills can serve as the basis for the development of training programs with the use of robots. In this case, the 
robots could detect the lack of formation or certain skills and offer simpler tasks for this particular skill until it is developed.

\section{Conclusion}

We conducted a study that provides further insights into the question of robot-tohuman interaction. Emotional gestures were particularly important to form positive impression of the interaction with the robot. However, emotional speech causes positive facial reactions such as smiles. During the interaction, the subjects demonstrate stable behavioral patterns: mark the choice of the game element and the completion of manipulations with a game element. Difficulties that regularly arise during the solution can be used in developing strategies for teaching a person by robot. For example, the robot should not only prompt the figure and its location in the contour, he also should advise turning the figure over (in particular, a parallelogram), skipping instructions if the child wants to assemble a puzzle by himself. The robot also has to detect certain behavioral cues: track the user's mimic and gesture reactions, marking of the choice of the game element, completion of actions or expression of the overall emotional reaction of the child.

Summarizing, we can say that the interaction of the robot with children of primary school age contributes to their development and learning. When the robot acts as a source of knowledge, younger schoolchildren show increased interest. The use of robots as learning assistants is an interesting and promising direction in the development of robotics.

\section{References}

1. Alemi, M., Meghdari, A., Ghazisaedy, M. (2014). Employing humanoid robots for teaching English language in Iranian junior high-schools. In International Journal of Humanoid Robotics, 11(03), 1450022.

2. Belpaeme, T., Kennedy, J., Ramachandran, A., Scassellati, B., Tanaka, F. (2018 a). Social robots for education: A review. In Science robotics. V. 3(21), eaat5954.

3. Belpaeme, T., Vogt, P., Van den Berghe, R., Bergmann, K., Göksun, T., De Haas, M., Papadopoulos, $F$. (2018b). In Guidelines for designing social robots as second language tutors. In International Journal of Social Robotics. V. 10(3), pp. 325-341.

4. Brown, L. N., Howard, A. M. (2014). The positive effects of verbal encouragement in mathematics education using a social robot. In IEEE integrated STEM education conference, pp. 1-5.

5. Brown, P., Levinson, S. C. (1987) Politeness: Some universals in language usage. Cambridge University Press.

6. Clark H. H., Wilkes-Gibbs D. (1986) Referring as a collaborative process, Cognition, pp. 1-39.

7. Cuadrado, L. E. I., Riesco, Á. M., de la Paz López, F. (2019). FER in Primary School Children for Affective Robot Tutors. In International Work-Conference on the Interplay Between Natural and Artificial Computation, pp. 461-471. Springer, Cham. 
8. Elkonin D. B. (1951) Thinking of primary school children [Myshlenie mladshego shkol'nika]. Essays on child psychology [Ocherki psihologii detej]. Moscow

9. Gordon, G., Breazeal, C., Engel, S. (2015). Can children catch curiosity from a social robot?. In Proceedings of the Tenth Annual ACM/IEEE International Conference on Human-Robot Interaction, pp. 91-98.

10. Han, J. H., Jo, M. H., Jones, V., Jo, J. H. (2008). Comparative study on the educational use of home robots for children. In Journal of Information Processing Systems, 4(4), 159-168.

11. Han, J. H., Kim, D. H., Kim, J. W. (2009). Physical learning activities with a teaching assistant robot in elementary school music class. In 2009 Fifth International Joint Conference on INC, IMS and IDC, pp. 1406-1410.

12. Han, J., Kim, D. (2009). r-Learning services for elementary school students with a teaching assistant robot. In 2009 4th ACM/IEEE International Conference on Human-Robot Interaction (HRI), pp. 255-256).

13. Kanda, T., Hirano, T., Eaton, D., Ishiguro, H. (2004). Interactive robots as social partners and peer tutors for children: A field trial. In Human-Computer Interaction. V. 19(1-2), pp. 61-84.

14. Kelley J. F. (1984) An iterative design methodology for user-friendly natural language office information applications, ACM Transactions on Office Information Systems, March 1984, V. 2(1), pp. 26-41.

15. Kennedy, J., Baxter, P., Belpaeme, T. (2015 a). The robot who tried too hard: Social behaviour of a robot tutor can negatively affect child learning. In 2015 10th ACM/ IEEE International Conference on Human-Robot Interaction (HRI), pp. 67-74.

16. Kennedy, J., Baxter, P., Senft, E., Belpaeme, T. (2015b). Higher nonverbal immediacy leads to greater learning gains in child-robot tutoring interactions. In International conference on social robotics, pp. 327-336. Springer, Cham.

17. Kirschner, D., Velik, R., Yahyanejad, S., Brandstötter, M., Hofbaur, M. (2016). YuMi, come and play with Me! A collaborative robot for piecing together a tangram puzzle. In International Conference on Interactive Collaborative Robotics, pp. 243-251.

18. Leite, I., Pereira, A. (2007). Icat, the affective chess player. In Proceedings of the systems demonstrations. Second international conference on Affective Computing and Intelligent Interaction (ACII 2007), pp. 29-33).

19. Leyzberg, D., Spaulding, S., Toneva, M., Scassellati, B. (2012). The physical presence of a robot tutor increases cognitive learning gains. In Proceedings of the annual meeting of the cognitive science society (Vol. 34, No. 34).

20. Mubin, O., Stevens, C. J., Shahid, S., Al Mahmud, A., Dong, J.-J. (2013). A review of the applicability of robots in education. In British Journal of Educational Technology. V. 1, pp.13.

21. Park, H. W., Rosenberg-Kima, R., Rosenberg, M., Gordon, G., Breazeal, C. (2017). Growing growth mindset with a social robot peer. In Proceedings of the 2017 ACM/IEEE International Conference on Human-Robot Interaction, pp. 137-145.

22. Pereira, A., Leite, I., Mascarenhas, S., Martinho, C., Paiva, A. (2010). Using empathy to improve human-robot relationships. In International Conference on $\mathrm{Hu}$ man-Robot Personal Relationship, pp. 130-138. Springer, Berlin, Heidelberg. 
23. Schodde, T., Hoffmann, L., Kopp, S. (2017). How to manage affective state in child-robot tutoring interactions? In 2017 International Conference on Companion Technology, pp. 1-6.

24. Shiomi, M., Kanda, T., Howley, I., Hayashi, K., Hagita, N. (2015). Can a social robot stimulate science curiosity in classrooms?. In International Journal of Social Robotics. V. 7(5), pp. 641-652.

25. Shore, T., Androulakaki, T., Skantze, G. (2018). KTH Tangrams: A Dataset for Research on Alignment and Conceptual Pacts in Task-Oriented Dialogue. In Eleventh International Conference on Language Resources and Evaluation (LREC 2018), pp. 768-775.

26. van den Berghe, R., Verhagen, J., Oudgenoeg-Paz, O., van der Ven, S., Leseman, P. (2019). Social robots for language learning: A review. In Review of Educational Research. V. 89(2), pp. 259-295.

27. Wainer, J., Feil-Seifer, D. J., Shell, D. A., Mataric, M. J. (2006). The role of physical embodiment in human-robot interaction. In ROMAN 2006-The 15th IEEE International Symposium on Robot and Human Interactive Communication, pp. 117-122.

28. Zinina A., Zaydelman L., Arinkin N., Kotov A. (2019). Non-verbal behavior of the robot companion: a contribution to the likeability. In Procedia Computer Science. Postproceedings of the 10th Annual International Conference on Biologically Inspired Cognitive Architectures, BICA. Elsevier. 